\title{
Self-Compassion Moderates the Association Between Body Dissatisfaction and Suicidal Ideation in Adolescents: A Cross-Sectional Study
}

\author{
Qi Fan ${ }^{1} \cdot$ Yang $\mathrm{Li}^{2} \cdot$ Yue $\mathrm{Gao}^{3} \cdot$ Nabi Nazari $^{4}$ (D) Mark D. Griffiths ${ }^{5}$
}

Accepted: 29 November 2021

(c) The Author(s), under exclusive licence to Springer Science+Business Media, LLC, part of Springer Nature 2021

\begin{abstract}
Identifying risk and protective factors for suicidal ideation during adolescence is essential for suicide prevention. One potential risk factor is body dissatisfaction which appears to peak during adolescence. The present study investigated the self-compassion buffering effects in the relationship between body dissatisfaction and suicidal ideation. A convenience sample comprising 580 adolescents (mean age 16.35 years; $S D=.87$; range 14-18 years) was recruited from public schools. The results indicated a strong positive association between body dissatisfaction and suicidal ideation (Cohen's $f^{2}=.25$ ). The association was significantly moderated by the self-compassion $(\beta=-.16, S E=.04, p=.01$, $t=2.4 .34, .95 \%$ CI $[-.16,-.01])$. Structural equation modeling analysis showed that the lack of self-kindness was associated with a moderate suicidal ideation level (Cohen's $f^{2}=.14$ ). Also, higher levels of self-judgment predicted suicidal ideation with a moderate to large effect size (Cohen's $f^{2}=.28$ ). The findings suggest that therapeutic programs designed to develop self-compassion should be implemented to reduce the risk of suicidal ideation among adolescents with body dissatisfaction. The findings empirically show that a higher degree of self-judgment is strongly associated with suicidal thoughts among adolescents, which must be systematically addressed in clinical studies on suicidal risk.
\end{abstract}

Keywords Suicidal ideation $\cdot$ Body image $\cdot$ Body dissatisfaction $\cdot$ Suicide $\cdot$ Selfcompassion · Adolescents

\section{Nabi Nazari}

Nazariirani@gmail.com

1 Institute of Mental Health, Nanjing Xiaozhuang University, Nanjing 210017, Jiangsu Province, China

2 Mental Health Education Center, Nanjing Forest Police College, Nanjing 210023, Jiangsu Province, China

3 Department of Psychology, School of Medicine \& Holistic Integrative Medicine, Nanjing University of Chinese Medicine, Nanjing 210023, Jiangsu Province, China

4 Department of Psychology, Faculty of Human Sciences, Lorestan University, Khorramabad, Iran

5 International Gaming Research Unit, Psychology Department, Nottingham Trent University, Nottingham, UK 


\section{Introduction}

Suicide is a major and complex public health issue, the risk of which increases throughout adolescence (aged 15-19 years) and is consistently ranked among the leading causes of death worldwide (Mars et al., 2019). The immense research efforts to date contribute to understanding of the risk factors related to suicidal behavior in adolescents. However, they are limited in their capability to enhance the prediction for future suicide and distinguish between suicide ideators and suicide attempters (May and Klonsky 2016). In order to address these limitations, a new generation of theories emerged. The ideation-to-action framework provided an integrative framework to inform suicide research (Klonsky et al., 2016).

Moreover, three complex suicide theories, including the Three-Step Theory (3ST; Klonsky \& May, 2015), the Integrated Motivational Volitional Model (IVM; O’Connor, 2011), and the Interpersonal Theory of Suicide (Joiner, 2005; Van Orden et al., 2011), are situated within this framework. These are theories that address the development of suicidal ideation and the progression from it to the suicide attempt. According to this framework, the progression of suicide ideation is a distinct process starting with suicide ideation progression and leading to possible suicide attempts with their specific conceptualizations and predictors (Zareian \& Klonsky, 2020). Therefore, identifying risk factors for suicidal ideation during adolescence is essential for suicide prevention. One such potential risk factor is body dissatisfaction. Similar to suicidality, body dissatisfaction prevalence appears to peak during adolescence. While adolescents may be more vulnerable to psychopathology and suicide behavior (Costanza et al., 2020), adolescence is a crucial developmental stage for the onset of suicidal ideation (Voss et al., 2019).

\section{Body Dissatisfaction}

Body dissatisfaction refers to an individual's negative feelings or thoughts about their body, including negative judgments about size, shape, and muscle tone (Cash \& Smolak, 2011\& Cash, 2012). According to the sociocultural model (Thompson et al., 1999), adolescents internalize appearance ideals based on feedback to related ideal bodies, provided by different social resources such as their parents and peers. Body dissatisfaction generally involves a negatively perceived discrepancy between individuals' evaluation of their actual and standard or ideal body and is the core mechanism of various eating disorders (American Psychiatric Association [APA] 2013). Given that suicide is one of the principal causes of mortality among individuals with eating disorders (Bhatt-Poulose et al., 2016; Greydanus \& Apple, 2011; Rufino et al., 2018), it can be hypothesized that body dissatisfaction is linked to suicide, a link that has already been directly and indirectly identified (Kim \& Kim, 2009; Perkins \& Brausch, 2019; Peterson et al., 2017). Among adolescents, body dissatisfaction predicts suicidal ideation progression beyond depression and hopelessness (Muehlenkamp \& Brausch, 2012). Also, suicidal adolescents report higher levels of body dissatisfaction and negative body feelings and lower body care and body assurance levels than non-suicidal adolescents (Brausch \& Muehlenkamp, 2007; Orbach et al., 2006). The negative impact of body dissatisfaction on mental health is well documented. For example, body dissatisfaction is closely related to the development of depressive symptoms (Bornioli et al., 2020), anxiety (Vannucci \& Ohannessian, 2018), lower self-esteem (Paxton et al., 2006), eating disorders (Freire et al., 2020), and psychological distress (Griffiths et al., 
2016), but has not received significant attention in identifying effective adaptive strategies in the face of body dissatisfaction. Despite the role of body image perception (e.g., body dissatisfaction, body shame) as a risk factor for suicidal ideation (Perkins et al., 2021), few studies have investigated this relationship. Particularly among boys, body dissatisfaction has rarely been deemed a problem, nor has it been given adequate attention within the body image field (Bucchianeri, \& Neumark-Sztainer, 2014).

\section{Self-Compassion}

To date, suicide studies have focused on the existence of risk factors, so there is a solid understanding of how these factors interact and contribute to risk. Despite significant breakthroughs in scientific understanding of the psychology of suicide, there are still many gaps in knowledge. The evidence on factors that could protect against suicide risk is particularly limited. The fact remains that most of the young adolescents suffering from psychopathology do not kill themselves. Therefore, although psychopathology is a major risk factor, it is not enough to explain the complexity of suicidal behavior. Although several established and helpful risk-reduction interventions are available in preventing suicide, identifying the protective factors has received less attention, and even less effort has been devoted to the role of protective factors in research and clinical practice. To counter the conventional approach emphasis toward disorders (e.g., risk factors and maladaptation), an important trend within psychology is the concentration on "positive psychology" (Seligman \& Csikszentmihalyi, 2000). Consistent with this trend, some scholars in the field of positive youth development (PYD) examining adolescence and youth have progressively incorporated a strengths-based approach, which seeks to strengthen the adolescent's assets to respond to developmental challenges adaptively. Also, research recognizes psychosocial characteristics and protective components, which are associated with reduced problems and increased well-being among adolescents (Lerner et al., 2015).

Self-compassion, a relatively new concept in psychology, has been defined as representing the balance between decreased negative and increased positive self-responding (Neff, 2003, 2016). Self-compassion is a multi-faceted construct with six dimensions: self-kindness, mindfulness, common humanity (positive self-responding), self-judgment, isolation, and over-identification (negative self-responding). The six components conceptually refer to different strategies and a range of individual responses that are implicated in difficult situations (Neff et al., 2019; Neff et al., 2021). The role of self-compassion is well-documented as a protective factor against the development, occurrence, and prevention of risk factors related to eating disorders and body dissatisfaction (Albertson et al., 2014; Barnett \& Sharp, 2016; Linardon et al., 2020; Turk \& Waller, 2020). Individuals with adverse childhood experiences may benefit from self-compassion as a protective factor against negative mood, weight, and eating-related consequences in the future. Because of this, self-compassion may be a significant intervention target for those who have had traumatic childhood experiences.

Self-compassion research has predominantly been conducted utilizing adult samples (e.g., university students). However, there is growing evidence that self-compassion could benefit adolescents (Cheang et al. 2019; Neff \& McGehee, 2010). More specifically, empirical studies indicate that self-compassion is a protective factor against anxiety (Gill et al., 2018), psychological distress (Pullmer et al., 2019), depression (Marsh et al., 2018), and post-traumatic disorders for adolescents. Self-compassion may also play a crucial role during traumatic events in reducing adverse psychological consequents, particularly among 
vulnerable groups such as children (Coyne et al., 2020). According to cross-sectional and experimental studies, the greater levels of self-compassion are associated with greater levels of positive outlook, satisfaction with the body, and specific goal achievement, as well as healthier physiological responses to stress and less depression or anxiety (Ferguson et al., 2014). However, the effect of self-compassion on suicidal ideation is understudied.

\section{The Present Study}

Body dissatisfaction and suicidal ideation tend to arise during adolescence and are considerably affected by social and interpersonal factors. A recent systematic review suggested a potential association between previous infectious disease-related public health emergencies and increased risk of suicidal thoughts and behavior (Zortea et al., 2021). Suicidality is one of the most extreme outcomes of illnesses such as COVID-19 (Costanza et al., 2020). The COVID-19 pandemic has been associated with problematic eating behaviors (Ramalho et al., 2021), lower physical activity (Puccinelli et al., 2021), and higher social media activities (Chen et al., 2021), all of which are risk factors in 3. Also, school closures, leading to considerable social isolation for students, have been considered one of the central factors in developing psychological health issues (e.g., lower social connectedness, higher social isolation, higher psychological distress, and higher depression), all of which can be risk factors for suicidal ideation (Sekowski et al., 2020). Therefore, understanding the factors that can help individuals cope positively with suicidal ideation is more critical than ever. Based on the positive youth development approach, to better understand the relationship between body concerns and suicidal ideation, researchers need to investigate the experiences of individuals' resources (i.e., self-compassion) concerning the body concerns.

Despite the high prevalence of major mental disorders among adolescents, specialist services are disproportionately focused on adults. The present study was conducted to contribute to the growing body of empirical evidence of the benefits of self-compassion during adolescence. Therefore, moderation analysis was carried out to examine whether self-compassion moderates the association between body dissatisfaction and suicidal ideation. More specifically, it was hypothesized that higher levels of self-compassion would act as a buffer against suicidal ideation for adolescents with higher body dissatisfaction levels. The second aim of the study was to examine the relationship between the three positive dimensions of self-compassion (i.e., self-kindness, common humanity, mindfulness) and the three negative dimensions of self-compassion (i.e., self-judgment, isolation, overidentification) with body dissatisfaction and suicidal ideation. Using structural equation modeling, it was hypothesized that the (i) positive dimensions of self-compassion would be negatively related to body dissatisfaction and suicidality and (ii) negative dimensions of self-compassion would be positively associated with body dissatisfaction and suicidality.

\section{Method}

\section{Participants and Ethics}

The participants comprised a convenience sample of 580 adolescents recruited via a webbased learning platform. The participants' mean age was 16.31 years $(S D=0.87$, range 
14-18 years), and $57.6 \%(n=334)$ of the sample was female. Eligibility criteria included (a) being able to read and complete a consent form and online survey, (b) being fluent in the Chinese language, (c) providing informed consent (including from one of their parents or legal guardians), and (d) no history of suicide attempts or psychiatric disorders and (e) serious suicidal ideation. The present study, including procedures, was reviewed and approved by the first author's university Ethics Committee. All participants provided online informed consent. Incorporating the STROBE checklist, the study was conducted from December 2020 to April 2021 (see Supplementary File 1).

\section{Measures}

Suicidal Ideation Questionnaire-Junior (SIQ-JR; Reynolds 1987) The 15-item SIQ-JR was used to assess suicidal ideation. The items were rated on a seven-point scale from 0 ("I never had this thought") to 6 ("almost every day"). The total raw scores range from 0 to 90. A higher score represents a higher severity of suicidal ideation. The scale's reliability was very good in $5(\alpha=0.88)$. For the present study, SIQ-JR total scores $\geq 31$ were determined as indicating serious suicidal ideation.

Self-Compassion Scale-Youth Version (SCS-Y; Neff et al., 2021) The 17-item SCS-Y was used to assess self-compassion among adolescents. The scale comprises six subscales assessing positive and negative dimensions of self-compassion. The SCS-Y items with items were responded on a five-point scale from 1 (almost never) to 5 (almost always) with negative dimensions reverse scored. The total raw scores range from 17 to 85 . The total mean of the six subscale means was used to calculate a total score. A higher score represents a higher self-compassion. The scale's reliability was very good in $5(\alpha=0.87)$. The Chinese version of SCS-Y was translated and validated in the parallel study (see supplementary data).

Body Dissatisfaction Subscale of Eating Disorder Inventory (EDI 3; Garner, 2004) The 10-item Body Dissatisfaction subscale of the EDI-3 was used to assess body dissatisfaction. Adolescents rated each items on a five-point scale from 0 (never) to four (always). The total raw scores range from 0 to 40 . A higher score represents greater body dissatisfaction. The subscale's reliability was very good in $5(\alpha=0.83)$.

Demographic Variables Participants were asked to indicate their age and gender. No other demographic information was asked for.

\section{Procedure}

Participant Recruitment The participants were enrolled from Chinese secondary schools utilizing a convenience sampling method over 10 weeks. In 5, a survey was sent to 19 secondary teachers who were all fully aware of the research. A specific online link was generated for each teacher, which their own pupils could only access. Teachers briefed the students, who then read the study's objectives and duration, assurances of anonymity, confidentiality, voluntary participation, and withdrawal without any consequences. Once the link was clicked, it led to an informed consent page that could be read and agreed upon before they proceeded to the survey questions. The provision of informed consent 
was provided by the students and their parents, teachers, or legal guardians. Parents could withdraw their children from the study by sending a note to the school. The teachers also assessed exclusion and inclusion criteria. Also, the teachers removed all student identifiers (i.e., personal data) before sending the online data to the research team.

To determine the sample size, a priori power analysis was performed for the moderation test using G-Power (Faul et al., 2009). The calculated sample size was 485 using $\alpha$ error of 0.05 , a Power (1- $\beta$ err prob) of 0.80 , a small effect size (Cohens $\left.f^{2}=0.02\right)$, and three predictors. A total sample size of 580 was recruited in 5, which allowed for a $15 \%$ loss of data.

\section{Data Analysis}

Means and SDs were calculated for all continuous variables. Chi-squares and independent sample $t$-tests were used to calculate the gender differences. The absolute skewness and kurtosis values assessed the normality assumption. The multi-collinearity issue was evaluated by a variance inflation factor (VIF). Pearson correlation coefficients $(r)$ were generated to calculate the variables' associations. The absolute skewness and kurtosis values were less than two, and the VIF values $(1<\mathrm{VIF}<3)$ suggested the absence of any multi-collinearity issue.

\section{Moderation Analysis}

PROCESS model 1 (Hayes, 2017) was conducted to confirm whether overall individual abilities in six dimensions of self-compassion moderated the effect of body dissatisfaction on suicidal ideation, using mean centered values. The moderation model is depicted conceptually (Panel A) and statistically (Panel B) in Fig. 1. The interaction effects of body dissatisfaction and self-compassion on suicidal ideation were also investigated. An indirect effect was statistically significant when the calculated $95 \%$ bias-corrected confidence interval (CI) did not include zero. The $95 \%$ CI was generated by the bias-corrected method for the point estimate with 5,000 bootstrapped samples (Hayes, 2017). Also, to visualize the moderation associations, simple regression slopes were illustrated at three levels (mean minus one standard deviation, mean, and mean plus one standard deviation) as moderator variables (self-compassion), with the predictor (body dissatisfaction) as the independent variable and the suicidal ideation as the dependent variable (see Fig. 1).

\section{Structural Equation Modeling}

Structural equation modeling (SEM) was conducted to investigate the effects of self-compassion dimensions on body dissatisfaction and suicidal ideation. Once the measurement models were fitted to the data, it was expected that the positive dimensions of self-compassion (including self-kindness, common humanity, and mindfulness) would be negatively related to body dissatisfaction and suicidality. Also, the negative dimension (including selfjudgment, isolation, and over-identification) would be positively associated with body dissatisfaction and suicidal ideation. The guidelines suggested by Hu and Bentler (1999) were considered in evaluating the goodness of fit the models (comparative fit index (CFI) and Tucker-Lewis index (TLI) $>0.95$, standardized root mean square residual $($ SRMR $)<0.06$ ), 


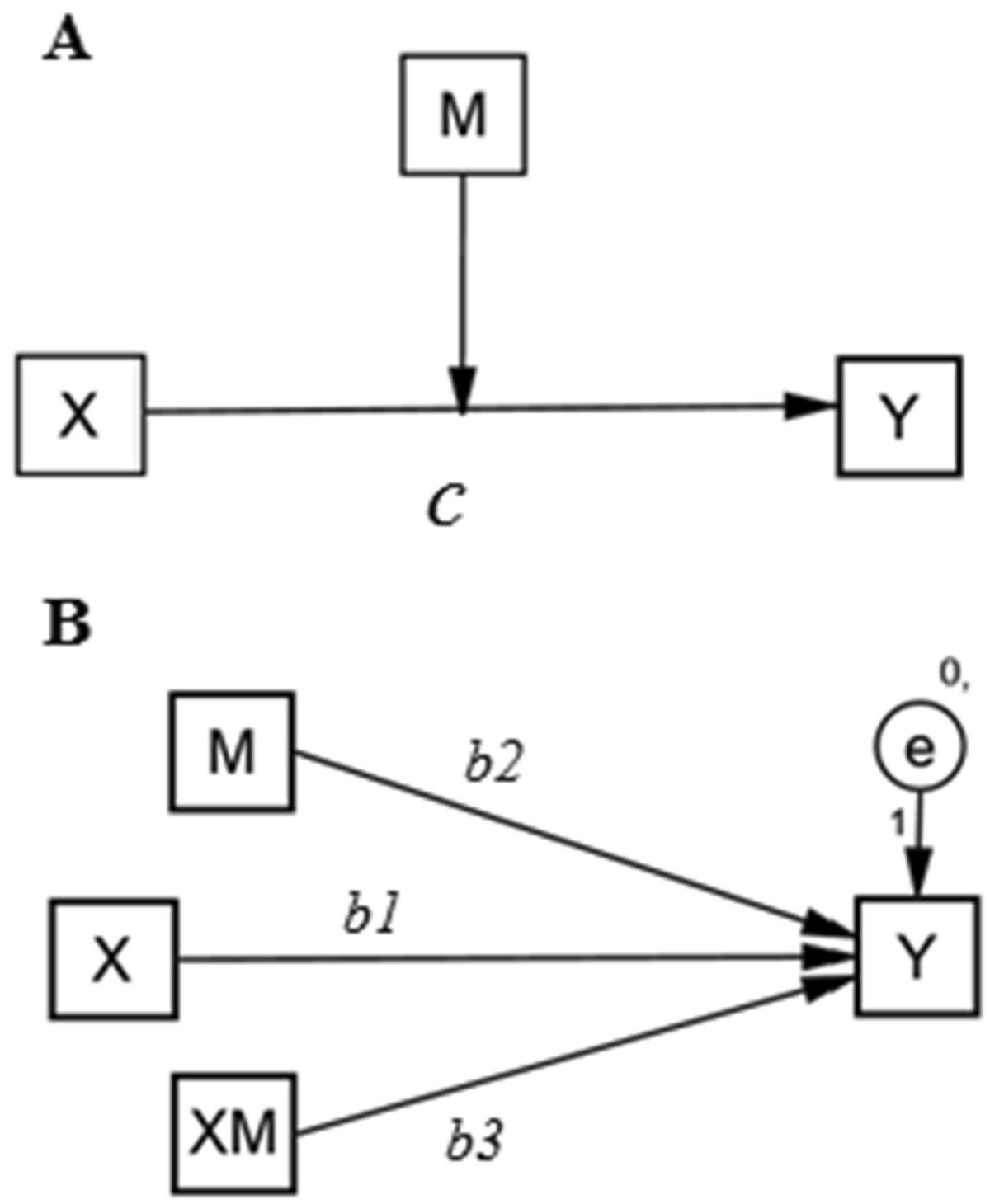

Fig. 1 Proposed model depicted conceptually (A) and statistically (B). X: Independent variable (body dissatisfaction). Y: Dependent variable (suicidal ideation). M: Moderator (self-compassion). XM: Body dissatisfaction $\times$ Self-compassion. Path c: Total effect of body dissatisfaction on suicidal ideation 
PCLOSE $>0.05$, and root mean square error of approximation (RMSEA) $<0.06$ ). The analyses were carried out using SPSS version 25 (SPSS Inc., Chicago, IL) and AMOS version 24(IBM Corp) with a two-sided alpha level $5 \%$ level of statistical significance.

\section{Results}

Descriptive statistics of the main variables are shown in Table 1. Evaluation of the skewness, kurtosis, and VIF values showed the absence of severe violations of normality and multi-collinearity risk (see Table 2 ). There were no significant participant differences in respect to gender. Females reported significantly higher scores than males concerning body dissatisfaction $(t[578]=2.45, p<0.01$, Cohen's $d=0.29)$. Age was significantly correlated with body dissatisfaction $(r=0.17 ; p<0.001)$ (i.e., older participants had higher body dissatisfaction). There was a large correlation between body

Table 1 Demographic characteristics of the sample $(N=580)$

\begin{tabular}{|c|c|c|c|c|}
\hline \multicolumn{5}{|l|}{ Categorical variables } \\
\hline & Frequency & Percentage & Chi-square test & $p$-value \\
\hline \multicolumn{5}{|l|}{ Gender } \\
\hline Men & 246 & 42.4 & $\chi^{2}=13.35$ & $<.001$ \\
\hline Women & 334 & 57.6 & & \\
\hline \multicolumn{5}{|l|}{ Age } \\
\hline 15 to 16 & 159 & 27.4 & & \\
\hline 16 to 17 & 200 & 34.5 & $\chi^{2}=10.28$ & .006 \\
\hline 17 to 18 & 221 & 38.1 & & \\
\hline \multicolumn{5}{|l|}{ Continuous variables } \\
\hline & Mean & $\mathrm{SD}$ & $t$-test & $p$-value \\
\hline Age (years) & 16.31 & .87 & $t(1,578)=1.90$ & .06 \\
\hline Body dissatisfaction & 30.77 & 7.71 & $t(1,578)=-2.45$ & $<.01$ \\
\hline Suicidal ideation & 24.19 & 9.34 & $t(1,578)=1.52$ & .13 \\
\hline Self-compassion & 29.67 & 7.00 & $t(1,578)=1.80$ & .07 \\
\hline
\end{tabular}

$S D$ standard deviation; negative $t$-value $=$ girls obtained higher score

Table 2 Correlation matrix of main study variables

\begin{tabular}{lllllllll}
\hline Variable & 1 & 2 & 3 & 4 & 5 & Skewness & Kurtosis & VIF \\
\hline 1-Body dissatisfaction & 1.00 & & & & .39 & .76 & 1.61 \\
2-Suicidal ideation & $.33^{* *}$ & 1.00 & & & & .18 & .71 & 1.64 \\
3-Self-compassion & $-.44^{* *}$ & $-.36^{* *}$ & 1.00 & & & .30 & .70 & 1.89 \\
4-Age & $-.17^{* *}$ & .05 & .04 & 1.00 & & N/A & N/A & N/A \\
5-Gender & .06 & -.08 & -.03 & $.10^{*}$ & 1.00 & N/A & N/A & N/A \\
\hline
\end{tabular}

N/A non applicable, VIF variance inflation factor ${ }^{* *} p<.001 ; * p<.05$ 
dissatisfaction and self-compassion $(r=-0.43 ; p<0.001,95 \%$ CI $[-0.53,-0.35])$ and a moderate correlation between suicidal ideation and self-compassion $(r=-0.36$; $p<0.001,95 \%$ CI $[-0.45,-0.28])$. Also, body dissatisfaction had a moderate correlation with suicidal ideation $(r=0.33 ; p<0.001,95 \%$ CI $[0.23,0.41])$. Correlation matrix is represented in Table 2.

\section{Moderation Results}

The standardized total effect of body dissatisfaction on suicidal ideation was statistically significant, with a moderate effect size (Cohen's $f^{2}=0.14,95 \%$ CI $[0.16,0.35]$ ). The standardized direct effect of body dissatisfaction significantly predicted suicidal ideation. Also, the interaction effect of body dissatisfaction and self-compassion (body dissatisfaction $\times$ Self-compassion) significantly predicted suicidal ideations, $\beta=-0.16$, $S E=0.04, p<0.001, t=4.34,95 \%$ CI $[0.23,0.42]$ and Cohens $d=0.05$. Therefore, selfcompassion partially moderated the link between body dissatisfaction and suicidal ideation. However, the effect size for a direct effect of the body dissatisfaction on suicidal ideation was no longer significant (see Table 3).

The simple slope for each interaction effect is shown in Fig. 2. For individuals with low scores (mean minus one standard deviation) $(\beta=0.32, S E=0.05, p<0.001, t=7.05$, 95\% CI $[0.23,0.42]$ ), on moderator variables (self-compassion), and average scores (mean) $\beta=0.14, S E=0.04, t=3.43, p=001,95 \%$ CI $[0.06,0.22]$, body dissatisfaction effects on suicidal ideation were statistically significant. However, for individuals who scored higher (mean plus one standard deviation) on moderator variable, the effect was not statistically significant $(\beta=0.03, S E=0.04, t=0.50, p=0.62,95 \%$ CI $[-0.08,0.13)$.

\section{Structural Equation Modeling}

The SEM analyses are reported in Table 4. The analysis produced excellent model fits for positive dimensions of self-compassion $\left(\chi^{2} / \mathrm{df}=1.5, \mathrm{CFI}=0.99, \mathrm{SRMR}=0.01\right.$, PCLOSE $=0.88>0.05$, RMSEA $=0.01,90 \%$ CI $[0.001,0.016])$ and for negative dimensions of self-compassion $\left(\chi^{2} / \mathrm{df}=1.5, \mathrm{CFI}=0.98, \mathrm{SRMR}=0.02, \mathrm{PCLOSE}=0.55>0.05\right.$, RMSEA $=0.02,90 \%$ CI $[0.011,0.029])$. Among the positive dimensions of self-compassion, self-kindness predicted suicidal ideation with a moderate effect size (Cohen's $f^{2}=0.15$ ). Among the negative dimensions, self-judgment predicted suicidal ideation with a moderate to large effect size (Cohen's $f^{2}=0.28$ ) (Table 4 and Fig. 3).

Table 3 Moderation analysis

\begin{tabular}{llllllll}
\hline Variable & Path & Beta & $S E$ & $p$-value & $t$-value & $95 \%$ CI & Cohen $f^{2}$ \\
\hline Body dissatisfaction $(\mathrm{X})$ & $c$ & .33 & 0.03 & $<.001$ & 7.39 & 0.24 to 0.41 & $\mathbf{. 1 3}$ \\
Body dissatisfaction $(\mathrm{X})$ & $b 1$ & .18 & 0.05 & $<.001$ & 3.66 & 0.09 to 0.27 & .03 \\
Self-compassion $(\mathrm{W})$ & $b 2$ & -.26 & 0.04 & $<.001$ & 6.75 & -.33 to -0.19 & $\mathbf{. 0 7}$ \\
Body dissatisfaction $\times \mathrm{SC}(\mathrm{XW})$ & $b 3$ & -.16 & 0.04 & $<.001$ & 4.34 & -.24 to -0.09 & $\mathbf{. 0 5}$ \\
\hline
\end{tabular}

$\left.\left.R^{2}=.20, F[3,576]=48.55, p<.001\right) . \Delta \mathrm{R}^{2}=.036, F[1,576]=26.22, p<.001\right)$

Note: SCS self-compassion; emboldened effect size $=$ significant value 


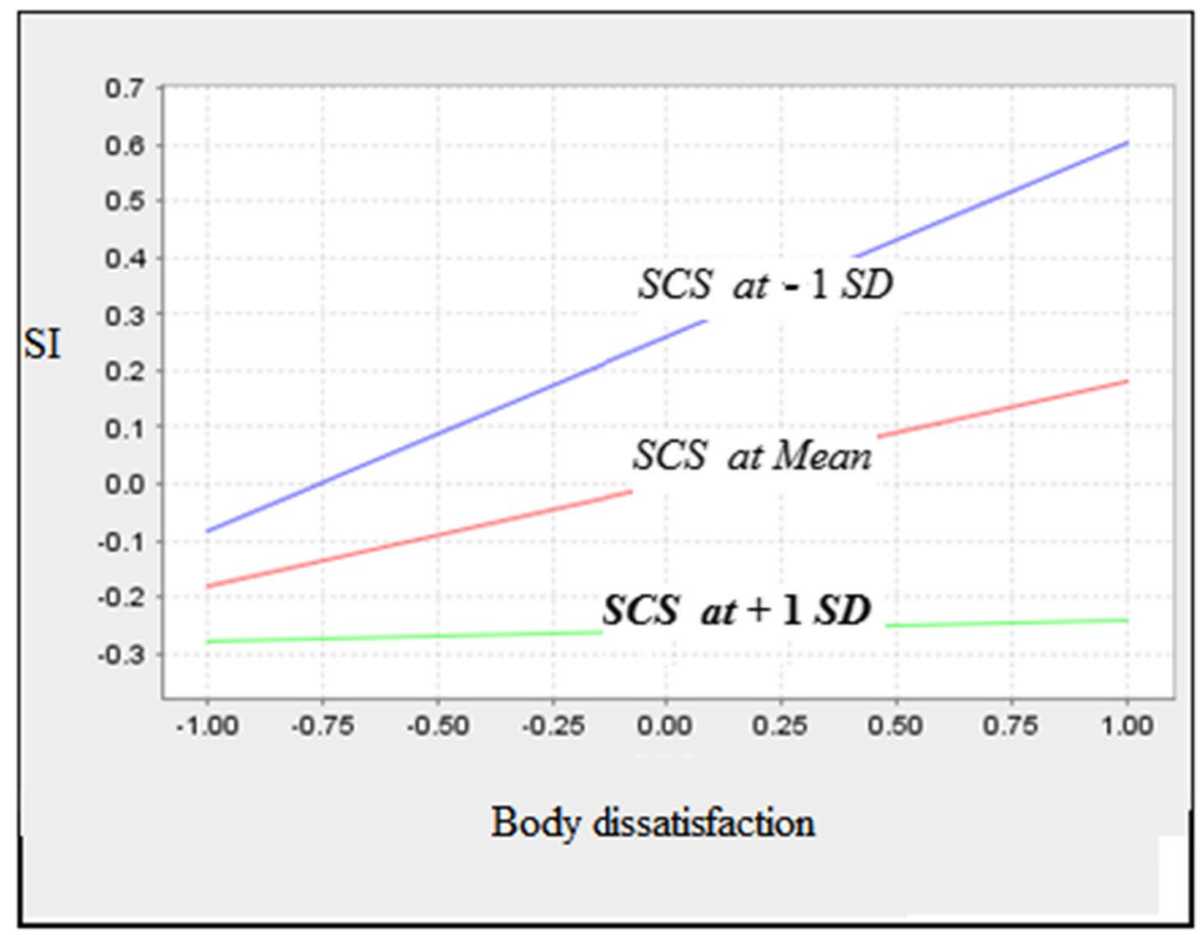

Fig. 2 The simple slope for interaction effect body dissatisfaction and self-compassion on suicidal ideation. Note: SCS, self-compassion; SI, suicidal ideation

\section{Discussion}

The present study investigated the self-compassion buffering effects in the relationship between body dissatisfaction and suicidal ideation. It was hypothesized that body dissatisfaction would predict suicidal ideation. It was also hypothesized that the association between body dissatisfaction and suicidal ideation would be moderated by self-compassion. The findings show that body dissatisfaction was associated with suicidal ideation, with moderate effect size, and that the association was moderated by self-compassion. The findings provide further support for the extant literature indicating that body dissatisfaction predicts suicidal ideation (Bhatt-Poulose et al., 2016; Greydanus \& Apple, 2011; Kim \& Kim, 2009; Perkins \& Brausch, 2019; Peterson et al., 2017; Rufino et al., 2018). Failure to attain society's standards for attractiveness may result in chronic and negative feelings and facilitate body dissatisfaction and social stigma. Negative body perception and feelings of unattractiveness are associated with affective disorder vulnerabilities, a sense of worthlessness, and hopelessness, all of which are predictors of suicide risk (Sick et al., 2020). As an individual skill, self-compassion plays a significant albeit modest role in suicidality. Self-compassion is considered learnable internal resources that can be enhanced via various therapeutic approaches (e.g., classic cognitive-behavioral therapy; Diedrich et al., 2014) and can be helpful in enhancing an individual's psychological well-being and reducing the impact of negative consequences of stressful events (Pyszkowska \& Rönnlund, 2021). 
Table 4 The standardized effects and effect size of structural equation modeling examining the relationship between the positive dimensions of self-compassion and the negative dimensions of self-compassion with body dissatisfaction and suicidal ideation

\begin{tabular}{|c|c|c|c|c|c|c|}
\hline Model and path & Beta & $S E$ & $p$-value & $t$-value & $95 \% \mathrm{CI}$ & Cohen $f^{2}$ \\
\hline \multicolumn{7}{|l|}{ Positive dimension of the SCS-Y } \\
\hline Self-kindness $->$ body dissatisfaction & -0.35 & 0.04 & $<.001$ & 8.36 & -0.39 to -0.24 & 0.15 \\
\hline Self-kindness $->$ suicidal ideation & -0.28 & 0.04 & $<.001$ & 6.98 & -0.35 to -0.19 & $\mathbf{0 . 0 7}$ \\
\hline $\begin{array}{l}\text { Common humanity }->\text { body dis- } \\
\text { satisfaction }\end{array}$ & -0.17 & 0.04 & $<.001$ & 3.77 & -0.25 to -0.08 & $\mathbf{0 . 0 3}$ \\
\hline $\begin{array}{l}\text { Common humanity }->\text { suicidal } \\
\text { ideation }\end{array}$ & -0.12 & 0.05 & 0.02 & 2.48 & -0.23 to -0.03 & 0.01 \\
\hline $\begin{array}{l}\text { Mindfulness }->\text { body dissatisfac- } \\
\text { tion }\end{array}$ & -0.29 & 0.05 & $<.001$ & 5.51 & -0.39 to -0.19 & 0.10 \\
\hline Mindfulness $->$ suicidal ideation & -0.24 & 0.04 & $<.001$ & 6.12 & -0.33 to -0.17 & 0.06 \\
\hline \multicolumn{7}{|l|}{ Negative dimension of the SCS-Y } \\
\hline $\begin{array}{l}\text { Self-judgment }->\text { body dissatisfac- } \\
\text { tion }\end{array}$ & 0.19 & 0.06 & $<.001$ & 3.56 & $0.09-0.30$ & 0.03 \\
\hline Self-judgment $->$ suicidal ideation & 0.48 & 0.05 & $<.001$ & 8.39 & $0.36-0.59$ & 0.28 \\
\hline Isolation $->$ body dissatisfaction & 0.14 & 0.04 & 0.01 & 2.46 & $0.02-0.27$ & 0.02 \\
\hline Isolation $->$ suicidal ideation & 0.01 & 0.06 & 0.80 & 0.25 & $-0.11-0.12$ & 0.00 \\
\hline $\begin{array}{l}\text { Over-identification-> body dis- } \\
\text { satisfaction }\end{array}$ & 0.30 & 0.06 & $<.001$ & 5.11 & $0.18-0.41$ & 0.08 \\
\hline $\begin{array}{l}\text { Over-identification }->\text { suicidal } \\
\text { ideation }\end{array}$ & 0.34 & 0.05 & $<.001$ & 6.46 & $0.21-0.40$ & 0.12 \\
\hline
\end{tabular}

SCS-Y Self-Compassion Scale Youth version; emboldened effect size = nonsignificant value

\section{Self-Compassion}

The study findings indicated that self-compassion buffered the effect of body dissatisfaction on suicidal ideation. Self-compassion appears to be effective in protecting against the impacts of negative body evaluation/comparison and body shame (Wollast et al., 2020; Callow et al., 2021). For most adolescents, self-criticism and self-attack are automation and habitual responses to rejection or failure, associated with suicidal ideation and psychopathological vulnerability (O'Neill et al., 2021). According to IMV theory (O'Connor, 2011), feeling entrapped can result from unpleasant and painful experiences (i.e., struggle with body dissatisfaction) and maladaptive responses (self-criticism and self-blame) when faced with unpleasant and painful experiences (body dissatisfaction, body shame). Less practical coping strategies, lower social support, and distorted cognitive biases contribute to developing entrapment feelings. Suicide ideation progresses when suicide is viewed as the only way the individual can escape from the entrapment. A stronger sense of self-compassion may be linked to feelings of control over stressors, facilitate adaptive coping, and be less likely to result in a negative attributional style. Especially in times of personal struggles, experiences of personal inadequacies, failures, and/or stressful life, self-compassion can reduce neuroticism and adverse effects through reductions in negative self-responding, such as shame and catastrophizing, a perspective that often leads to the development of hopelessness (Hayes et al., 2016; Li et al., 2021). In relation to the Interpersonal-Psychological Theory of Suicide, Baertschi et al. (2018) reported that among 


\section{Model A}

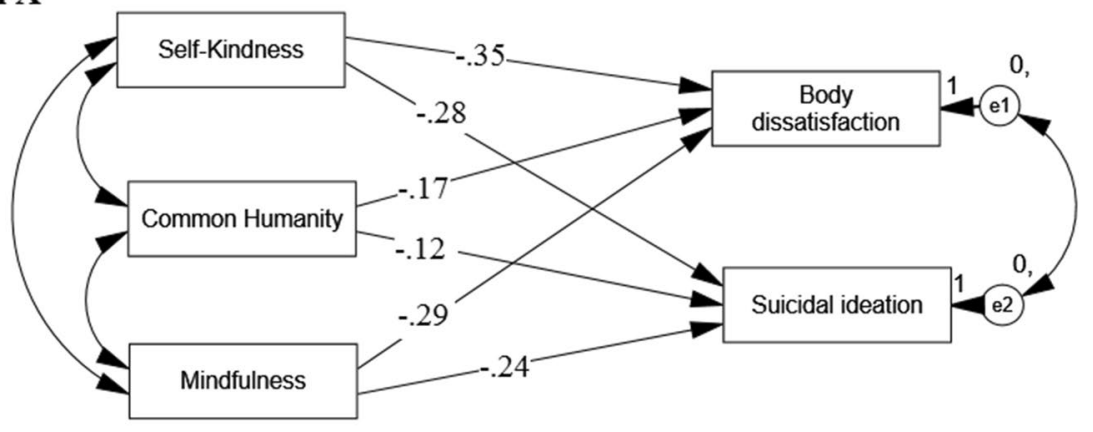

\section{Model B}

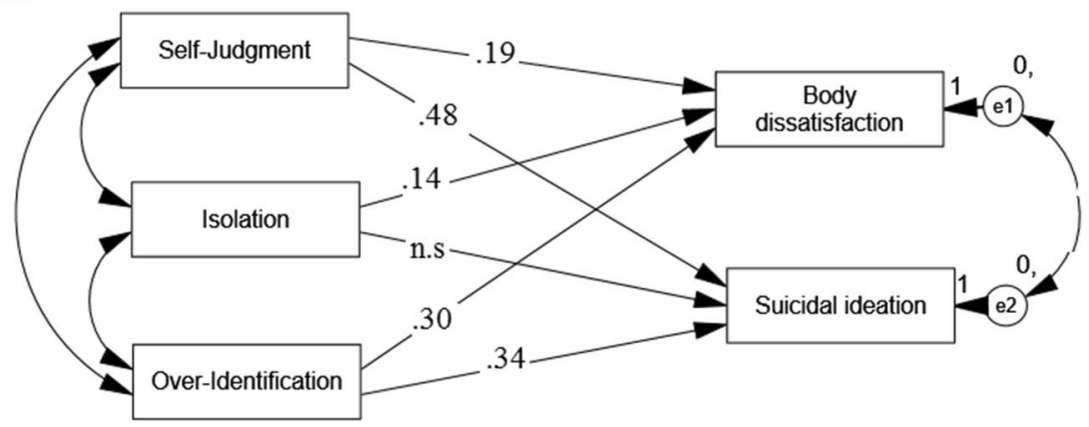

Fig. 3 Structural equation model of effects of self-compassion dimensions on body dissatisfaction and suicidal ideation. Model A: Positive dimensions (including self-kindness, common humanity, and mindfulness). Model B: Negative dimensions (including self-judgment, isolation, and over-identification)

the Big Five personality traits, lower extraversion and higher conscientiousness and lower extraversion were key predictors of the acquired capability for suicide.

The impact of body dissatisfaction on suicidal ideation was lower for adolescents with high self-compassion than for individuals with lower levels of self-compassion. The study findings replicate an increasing number of studies showing a negative association between selfcompassion and psychopathology vulnerability (Werner et al., 2012; Pérez-Aranda et al., 2021). Additionally, adaptive emotion functioning such as self-compassion is a viable predictor of subsequent psychopathology in early adolescence than in later adolescence. Moreover, promoting adaptive coping strategies during early adolescence may reduce the risk of internalizing disorders in the later stages of adolescence and emerging adulthood. While self-compassion predicts optimism, there is evidence indicating that traits related to optimism, such as self-compassion, facilitate recovery from the impacts of trauma and other mental health symptoms (Nazari et al., 2021). Self-compassion is also beneficial for the psychological adjustment and may also improve biological functioning (Pyszkowska \& Rönnlund, 2021). Self-compassion seems particularly relevant for those experiencing more negative life events. Self-compassion and its six subscales may address the different ways that individuals emotionally respond to suffering (with kindness or judgment), cognitively understand their predicament (as part of the human experience or as isolating), and the way individuals pay attention to pain (in a mindful or over-identified manner) (Zeller et al., 2015). Being (i) kind instead of harshly judging, (ii) aware in a mindful manner about painful experiences instead of avoiding, and (iii) connected instead of being isolated may 
offer positive coping strategies and act as buffers against psychopathology vulnerabilities (McKay \& Walker, 2021; Nerini et al., 2019; Zessin et al., 2015). Self-kindness, nonjudgmental attitude, and non-over-identification are all associated with decentring. Decentring refers to an individual's ability to deal with beliefs and thoughts as the ephemeral or transient and subjective inner circumstances or events. Decentring is negatively associated with body dissatisfaction (Palmeira et al., 2014) and positively associated with body appreciation (de Wet et al., 2020). The mindfulness component of self-compassion is associated with selfobjectification (Cox et al. 2016) and body shame and dissatisfaction (Adams et al., 2012). Another component of self-compassion is that common humanity may help to recognize that body imperfection is part of a more extensive human experience. Consistent with growing literature, self-compassion studies reported the significant associations between higher levels of self-compassion and lower levels of suicidal ideation.

\section{Practical Implications}

The present study's findings have implications in preventing or reducing body dissatisfaction among adolescents and prevention and intervention of suicidal ideation among adolescents. Self-compassion programs may be effective interventions that help reduce body dissatisfaction and its consequences such as suicidal ideation. The present study's findings support the cumulative buffering effect of self-compassion in inhibiting body dissatisfaction on suicidal ideation. The results suggest the potential positive influence of self-compassion being incorporated into therapeutic programs designed to reduce suicidal ideation. For example, a self-compassion intervention in a peer-group format or a schoolbased intervention to enhance self-compassion may be considered in future research. The adapted mindful self-compassion intervention for adolescents is an effective intervention to enhance connectedness (Bluth et al., 2016). Self-compassion interventions in family therapy formats (e.g., compassion-focused parenting as a form of parenting intervention [Kirby, 2019]) or in combination with social skill training programs may be potentially more robust interventions than standard intervention formats in reducing suicidal ideation and body dissatisfaction. Applying suicide interventions at a family level to adolescents may strengthen the intervention effects. However, there is little data concerning such interventions. During the COVID-19 pandemic, parents have played a critical role in early intervention for adolescents with eating disorders and need further support on how to (and how not to) speak with children about eating or body concerns. As schools reopen, adolescents should be taught how to cope with body dissatisfaction more effectively. Also, school mental health programs are important for all children, and targeted approaches will be necessary for those more severely affected by the psychosocial impact of the pandemic.

\section{Limitations}

The present study has several limitations, notably related to the participants recruited and the type of data collected. The study was conducted during the COVID-19 pandemic. Therefore, to minimize infection risk, online data collection was utilized rather than faceto-face methods. Data were collected using self-report instruments, which are subject to well-established common methods biases. However, the online data collection method tends to provide more honest and truthful responses than those utilizing offline and/or faceto-face methods (Griffiths, 2010). Also, the stressful pandemic situation may have been a confounding factor that elevated mental health problems and higher than usual daily 
psychological life distress among the participants. Finally, the study was cross-sectional. Therefore, determining causality between the study's variables was not possible.

\section{Conclusion}

The findings make a significant contribution to the expanding literature on body dissatisfaction and suicidality among adolescents. Within the PYD framework, the study's findings provide a foundation for future research regarding the combined role of body dissatisfaction and individual assets and suicidal ideation. The present study demonstrates the critical role of body dissatisfaction in the progression of suicidal ideation among both girls and boys. The findings suggest the potential positive cumulative influence of variables that could be incorporated into therapeutic programs designed to develop self-compassion as a way of inhibiting or preventing suicidal ideation among adolescents experiencing body dissatisfaction. The findings also support the importance of specific self-compassion components which could also be incorporated into prevention programs to reduce suicidal ideation. The findings empirically show that a higher degree of self-judgment is strongly associated with suicidal thoughts among adolescents, which must be systematically addressed in clinical studies on suicidal risk.

Supplementary Information The online version contains supplementary material available at https://oi. org/10.1007/s11469-021-00727-4.

Acknowledgements Jiangsu Universities in Philosophy and Social Science Foundation (2019SJA0430): A New Exploration of Minors' Mental Health Education Model under the Background of Embodied Cognition: A Case Study of Primary and Middle School Students in Nanjing

Author Contribution NN and QF conceived and planned the study. YL and YG collected the data. MDG supervised the study. All authors contributed to write the manuscript. MDG edited the final manuscript including the revised version.

Data Availability The data that support the findings of this study are available on request from the corresponding author.

\section{Declarations}

Ethics Approval and Consent to Participate The study has been performed in accordance with the Declaration of Helsinki and has been approved and registered by the ethical and research committees from the following collaborating centers. The study, including all assessments and procedures for the study, was reviewed by the first author's Institutional Human Research Ethics Committee (code 11466). All participants provided a signed written consent.

Competing Interests The authors declare no competing interests.

\section{References}

Adams, C. E., Apperson McVay, M., Kinsaul, J., Benitez, L., Vinci, C., Stewart, D. W., \& Copeland, A. L. (2012). Unique relationships between facets of mindfulness and eating pathology among female smokers. Eating Behaviors, 13(4), 390-393. https://doi.org/10.1016/j.eatbeh.2012.05.009

Albertson, E. R., Neff, K. D., \& Dill-Shackleford, K. E. (2014). Self-compassion and body dissatisfaction in women: A randomized controlled trial of a brief meditation intervention. Mindfulness, 6(3), 444-454. https://doi.org/10.1007/s12671-014-0277-3 
American Psychiatric Association. (2013). Diagnostic and statistical manual of mental disorders (5th ed.). American Psychiatric Publishing.

Barnett, M. D., \& Sharp, K. J. (2016). Maladaptive perfectionism, body image satisfaction, and disordered eating behaviors among U.S. college women: The mediating role of self-compassion. Personality and Individual Differences, 99, 225-234. https://doi.org/10.1016/j.paid.2016.05.004

Baertschi, M., Costanza, A., Canuto, A., \& Weber, K. (2018). The function of personality in suicidal ideation from the perspective of the interpersonal-psychological theory of suicide. International Journal of Environmental Research and Public Health, 15(4), 636. https://doi.org/10.3390/ijerph15040636

Bhatt-Poulose, K., James, K., Reid, M., Harrison, A., \& Asnani, M. (2016). Increased rates of body dissatisfaction, depressive symptoms, and suicide attempts in Jamaican teens with sickle cell disease. Paediatric Blood and Cancer, 63(12), 2159-2166. https://doi.org/10.1002/pbc.26091

Bluth, K., Campo, R. A., Futch, W. S., \& Gaylord, S. A. (2016). Age and gender differences in the associations of self-compassion and emotional well-being in a large adolescent sample. Journal of Youth and Adolescence, 46(4), 840-853. https://doi.org/10.1007/s10964-016-0567-2

Bornioli, A., Lewis-Smith, H., Slater, A., \& Bray, I. (2020). Body dissatisfaction predicts the onset of depression among adolescent females and males: A prospective study. Journal of Epidemiology and Community Health, 75(4), 343-348. https://doi.org/10.1136/jech-2019-213033

Brausch, A. M., \& Muehlenkamp, J. J. (2007). Body image and suicidal ideation in adolescents. Body Image, 4(2), 207-212. https://doi.org/10.1016/j.bodyim.2007.02.001

Bucchianeri, M. M., \& Neumark-Sztainer, D. (2014). Body dissatisfaction: An overlooked public health concern. Journal of Public Mental Health, 13(2), 64-69. https://doi.org/10.1108/jpmh-11-2013-0071

Cash, T. F., \& Smolak, L. (2011). Understanding body images: Historical and contemporary perspectives. In T. F. Cash \& L. Smolak (Eds.), Body image: A handbook of science, practice, and prevention (2nd ed., pp. 3-11). The Guilford Press.

Callow, T. J., Moffitt, R. L., \& Neumann, D. L. (2021). External shame and its association with depression and anxiety: The moderating role of self-compassion. Australian Psychologist, 56(1), 70-80. https:// doi.org/10.1080/00050067.2021.1890984

Cash, T. F. (2012). Cognitive-behavioral perspectives on body image. In T. F. Cash (Ed.), Encyclopedia of body image and human appearance (pp. 334-342). London, UK: Elsevier Science \& Technology.

Chen, C.-Y., \& Chen, I-Hua., O’Brien, K. S., Latner, J. D., \& Lin, C.-Y. (2021). Psychological distress and internetrelated behaviors between schoolchildren with and without overweight during the COVID-19 outbreak. International Journal of Obesity, 45(2021), 677-686. https://doi.org/10.1038/s41366-021-00741-5

Cohen, J. (1988). Statistical power analysis for the behavioral sciences (second ed.). London: Routledge https://doi.org/10.4324/9780203771587

Costanza, A., Rothen, S., Achab, S., Thorens, G., Baertschi, M., Weber, K., Canuto, A., Richard-Lepouriel, H., Perroud, N., \& Zullino, D. (2020). Impulsivity and impulsivity-related endophenotypes in suicidal patients with substance use disorders: An exploratory study. International Journal of Mental Health and Addiction, 19(8), 1729-1744. https://doi.org/10.1007/s11469-020-00259-3

Coyne, L. W., Gould, E. R., Grimaldi, M., Wilson, K. G., Baffuto, G., \& Biglan, A. (2020). First things first: Parent psychological flexibility and self-compassion during COVID-19. Behavior Analysis in Practice. Advance online publication. https://doi.org/10.1007/s40617-020-00435-w

De Wet, A. J., Lane, B. R., \& Mulgrew, K. E. (2020). A randomised controlled trial examining the effects of self-compassion meditations on women's body image. Body Image, 35, 22-29. https://doi.org/10. 1016/j.bodyim.2020.07.009

Diedrich, A., Grant, M., Hofmann, S. G., Hiller, W., \& Berking, M. (2014). Self-compassion as an emotion regulation strategy in major depressive disorder. Behaviour Research and Therapy, 58, 43-51. https:// doi.org/10.1016/j.brat.2014.05.006

Faul, F., Erdfelder, E., Lang, A.-G., \& Buchner, A. (2009). Statistical power analyses using G*Power 3.1: Tests for correlation and regression analyses. Behavior Research Methods, 41(4), 1149. https://doi.org/ 10.3758/BRM.41.4.1149

Ferguson, L. J., Kowalski, K. C., Mack, D. E., \& Sabiston, C. M. (2014). Exploring self-compassion and eudaimonic well-being in young women athletes. Journal of Sport and Exercise Psychology, 36(2), 203-216. https://doi.org/10.1123/jsep.2013-0096

Freire, G., da Silva Paulo, J. R., da Silva, A. A., Batista, R., Alves, J., \& do Nascimento Junior, J. (2020). Body dissatisfaction, addiction to exercise and risk behaviour for eating disorders among exercise practitioners. Journal of Eating Disorders, 8, 23. https://doi.org/10.1186/s40337-020-00300-9

Garner, D. M. (2004). Eating Disorder Inventory-3. Professional Manual. Lutz, FL: Psychological Assessment Resources, Inc.

Gill, C., Watson, L., Williams, C., \& Chan, S. W. Y. (2018). Social anxiety and self-compassion in adolescents. Journal of Adolescence, 69, 163-174. https://doi.org/10.1016/j.adolescence.2018.10.004 
Greydanus, D., \& Apple, R. W. (2011). The relationship between deliberate self-harm behavior, body dissatisfaction, and suicide in adolescents: Current concepts. Journal of Multidisciplinary Healthcare, 4, 183-189. https://doi.org/10.2147/jmdh.s11569

Griffiths, M. D. (2010). The use of online methodologies in data collection for gambling and gaming addictions. International Journal Mental Health and Addiction, 8(1), 8-20. https://doi.org/10.1007/ s11469-009-9209-1

Griffiths, S., Hay, P., Mitchison, D., Mond, J. M., McLean, S. A., Rodgers, B., Massey, R., \& Paxton, S. J. (2016). Sex differences in the relationships between body dissatisfaction, quality of life and psychological distress. Australian and New Zealand Journal of Public Health, 40(6), 518-522. https://doi.org/ $10.1111 / 1753-6405.12538$

Hayes, A. F. (2017). Introduction to mediation, moderation, and conditional process analysis: A regressionbased approach. (2nd ed.). Guilford Publications.

Hayes, J. A., Lockard, A. J., Janis, R. A., \& Locke, B. D. (2016). Construct validity of the self-compassion scale-short form among psychotherapy clients. Counselling Psychology Quarterly, 29(4), 405-422. https://doi.org/10.1080/09515070.2016.1138397

Hirsch, J. K., Chang, E. C., \& KelliherRabon, J. (2018). A positive psychological approach to suicide: Theory, research, and prevention. Springer.

Hu, L. T., \& Bentler, P. M. (1999). Cutoff criteria for fit indexes in covariance structure analysis: Conventional criteria versus new alternatives. Structural Equation Modeling, 6(1), 1-55. https://doi.org/10. $1080 / 10705519909540118$

Joiner, T. (2005). Why people die by suicide. Harvard University Press.

Kim, D., \& Kim, H. (2009). Body-image dissatisfaction as a predictor of suicidal ideation among Korean boys and girls in different stages of adolescence: A two-year longitudinal study. Journal of Adolescent Health, 45(1), 47-54. https://doi.org/10.1016/j.jadohealth.2008.11.017

Kirby, J. N. (2019). Nurturing family environments for children: Compassion-focused parenting as a form of parenting intervention. Education Sciences, 10(1), 3. https://doi.org/10.3390/educsci10010003

Klonsky, E. D., \& May, A. M. (2015). The three-step theory (3ST): A new theory of suicide rooted in the 'ideation-to-action' framework. International Journal of Cognitive Therapy, 8(2), 114-129. https://doi. org/10.1521/ijct.2015.8.2.114

Klonsky, E. D., May, A. M., \& Saffer, B. Y. (2016). Suicide, suicide attempts, and suicidal ideation. Annual Review of Clinical Psychology, 12(1), 307-330. https://doi.org/10.1146/annurev-clinp sy-021815-093204

Klonsky, E. D., Saffer, B. Y., \& Bryan, C. J. (2018). Ideation-to-action theories of suicide: A conceptual and empirical update. Current Opinion in Psychology, 22, 38-43.

Lerner, R. M., Lerner, J. V., Bowers, E., \& Geldhof, G. J. (2015). Positive youth development: A relational developmental systems model. In W. F. Overton, \& P. C. Molenaar (Eds.), Handbook of child psychology and developmental science. Vol. 1: Theory and method (7th ed.) (pp. 607-651). Hoboken, NJ: Wiley

Li, A., Wang, S., Cai, M., Sun, R., \& Liu, X. (2021). Self-compassion and life-satisfaction among Chinese self-quarantined residents during COVID-19 pandemic: A moderated mediation model of positive coping and gender. Personality and Individual Differences, 170(19), 110457. https://doi.org/10.1016/j. paid.2020.110457

Linardon, J., Susanto, L., Tepper, H., \& Fuller-Tyszkiewicz, M. (2020). Self-compassion as a moderator of the relationships between shape and weight overvaluation and eating disorder psychopathology, psychosocial impairment, and psychological distress. Body Image, 33, 183-189. https://doi.org/10.1016/j.bodyim. 2020.03.001

Marsh, I. C., Chan, S., \& MacBeth, A. (2018). Self-compassion and psychological distress in adolescents A meta-analysis. Mindfulness, 9(4), 1011-1027. https://doi.org/10.1007/s12671-017-0850-7

Mars, B., Heron, J., Klonsky, E. D., Moran, P., Connor, R. C. O., Tilling, K., .. Gunnell, D. (2019) Predictors of future suicide attempt among adolescents with suicidal thoughts or non-suicidal self-harm: A population-based birth cohort study. The Lancet Psychiatry, 366(19), 10-14. https://doi.org/10.1016/ S2215-0366(19)30030-6.

McKay, T., \& Walker, B. R. (2021). Mindfulness, self-compassion and wellbeing. Personality and Individual Differences, 168, 110412. https://doi.org/10.1016/j.paid.2020.110412

Muehlenkamp, J. J., \& Brausch, A. M. (2012). Body image as a mediator of non-suicidal self-injury in adolescents. Journal of Adolescence, 35(1), 1-9. https://doi.org/10.1016/j.adolescence.2011.06.010

Nazari, N., Zekiy, A. O., Feng, L. S., \& Griffiths, M. D. (2021). Psychometric validation of the Persian version of the COVID-19-Related Psychological Distress Scale and association with COVID-19 Fear, COVID-19 anxiety, optimism, and lack of resilience. International Journal of Mental Health and Addiction. Advance online publication. https://doi.org/10.1007/s11469-021-00540-Z 
Neff, K. D. (2003). Self-compassion scale. Self and Identity, 2, 223-250. https://doi.org/10.1080/1529886039 0209035

Neff, K. D. (2016). The self-compassion scale is a valid and theoretically coherent measure of self-compassion. Mindfulness, 7(1), 264-274. https://doi.org/10.1007/s12671-015-0479-3

Neff, K. D., Bluth, K., Tóth-Király, I., Davidson, O., Knox, M. C., Williamson, Z., \& Costigan, A. (2021). Development and validation of the self-compassion scale for youth. Journal of Personality Assessment, 103, 92-105. https://doi.org/10.1080/00223891.2020.1729774

Neff, K. D., \& McGehee, P. (2010). Self-compassion and psychological resilience among adolescents and young adults. Self and Identity, 9(3), 225-240. https://doi.org/10.1080/15298860902979307

Neff, K. D., Tóth-Király, I., Yarnell, L. M., Arimitsu, K., Castilho, P., Ghorbani, N., .. Mantzios, M. (2019). Examining the factor structure of the Self-Compassion Scale in 20 diverse samples: Support for use of a total score and six subscale scores. Psychological Assessment, 31(1), 27-45. https://doi.org/10.1037/pas00 00629

Nerini, A., Matera, C., Di Gesto, C., Policardo, G. R., \& Stefanile, C. (2019). Exploring the links between selfcompassion, body dissatisfaction, and acceptance of cosmetic surgery in young Italian women. Frontiers in Psychology, 10, 2698. https://doi.org/10.3389/fpsyg.2019.02698

O'Connor, R. C. (2011). Towards an integrated motivational-volitional model of suicidal behaviour. In R. C. O'Connor, S. Platt, \& J. Gordon (Eds.), International handbook of suicide prevention: Research, policy and practice (pp.181-198). Wiley Blackwell. https://doi.org/10.1002/9781119998556.ch11.

O’Neill, C., Pratt, D., Kilshaw, M., Ward, K., Kelly, J., \& Haddock, G. (2021). The relationship between selfcriticism and suicide probability. Clinical Psychology \& Psychotherapy. https://doi.org/10.1002/cpp.2593. Advanceonlinepublication.10.1002/cpp.2593

Orbach, I., Gilboa-Schechtman, E., Sheffer, A., Meged, S., Har-Even, D., \& Stein, D. (2006). Negative bodily self in suicide attempters. Suicide and Life-Threatening Behavior, 36(2), 136-153. https://doi.org/10.1521/ suli.2006.36.2.136

Paxton, S. J., Neumark-Sztainer, D., Hannan, P. J., \& Eisenberg, M. E. (2006). Body dissatisfaction prospectively predicts depressive mood and low self-esteem in adolescent girls and boys. Journal of Clinical Child \& Adolescent Psychology, 35(4), 539-549. https://doi.org/10.1207/s15374424jccp3504_5

Palmeira, L., Trindade, I. A., \& Ferreira, C. (2014). Can the impact of body dissatisfaction on disordered eating be weakened by one's decentering abilities? Eating Behaviors, 15(3), 392-396. https://doi.org/10.1016/j. eatbeh.2014.04.012

Perkins, N. M., Ortiz, S. N., Smith, A. R., \& Brausch, A. M. (2021). Suicidal ideation and eating disorder symptoms in adolescents: The role of interoceptive deficits. Advance online publication. https://doi.org/10. 1016/j.beth.2021.03.005

Perkins, N. M., \& Brausch, A. M. (2019). Body dissatisfaction and symptoms of bulimia nervosa prospectively predict suicide ideation in adolescents. International Journal of Eating Disorders, 52(8), 941-949. https:// doi.org/10.1002/eat.23116

Peterson, C. M., Matthews, A., Copps-Smith, E., \& Conard, L. A. (2017). Suicidality, self-harm, and body dissatisfaction in transgender adolescents and emerging adults with gender dysphoria. Suicide and LifeThreatening Behavior, 47(4), 475-482. https://doi.org/10.1111/sltb.12289

Puccinelli, P. J., da Costa, T. S., Seffrin, A., de Lira, C. A. B., Vancini, R. L., Nikolaidis, P. T., Knechtle, B., Rosemann, T., Hill, L., \& Andrade, M. S. (2021). Reduced level of physical activity during COVID-19 pandemic is associated with depression and anxiety levels: An internet-based survey. BMC Public Health, 21, 425. https://doi.org/10.1186/s12889-021-10470-Z

Pullmer, R., Coelho, J. S., \& Zaitsoff, S. L. (2019). Kindness begins with yourself: The role of self-compassion in adolescent body satisfaction and eating pathology. International Journal of Eating Disorders, 52(7), 809-816. https://doi.org/10.1002/eat.23081

Pyszkowska, A., \& Rönnlund, M. (2021). Psychological flexibility and self-compassion as predictors of wellbeing: Mediating role of a balanced time perspective. Frontiers in Psychology, 12, 2110. https://doi.org/10. 3389/fpsyg.2021.671746

Ramalho, S. M., Trovisqueira, A., de Lourdes, M., Gonçalves, S., Ribeiro, I., Vaz, A. R., Machado, P. P. P., \& Conceição, E. (2021). The impact of COVID-19 lockdown on disordered eating behaviors: The mediation role of psychological distress. Eating and Weight Disorders - Studies on Anorexia, Bulimia and Obesity., 7(3), 340-364. https://doi.org/10.1007/s40519-021-01128-1

Reynolds, W. M. (1987). Suicidal ideation questionnaire (SIQ). Odessa, FL: Psychological Assessment Resources.

Rufino, K. A., Viswanath, H., Wagner, R., \& Patriquin, M. A. (2018). Body dissatisfaction and suicidal ideation among psychiatric inpatients with eating disorders. Comprehensive Psychiatry, 84, 22-25. https://doi.org/ 10.1016/j.comppsych.2018.03.013 
Seligman, M. E. P., \& Csikszentmihalyi, M. (2000). Positive psychology: An introduction. American Psychologist, 55(1), 5-14. https://doi.org/10.1037/0003-066x.55.1.5

Sick, K., Pila, E., Nesbitt, A., \& Sabiston, C. M. (2020). Does self-compassion buffer the detrimental effect of body shame on depressive symptoms? Body Image, 34, 175-183. https://doi.org/10.1016/j.bodyim.2020. 05.012

Sekowski, M., Gambin, M., Cudo, A., Wozniak-Prus, M., Penner, F., Fonagy, P., \& Sharp, C. (2020). The relations between childhood maltreatment, shame, guilt, depression and suicidal ideation in inpatient adolescents. Journal of Affective Disorders, 276(2), 667-677. https://doi.org/10.1016/j.jad.2020.07.056

Thompson, J. K., Heinberg, L. J., Altabe, M., \& Tantleff-Dunn, S. (1999). Exacting beauty: Theory, assessment, and treatment of body image disturbance. American Psychological Association. https://doi.org/10.1037/ 10312-000

Trompetter, H. R., de Kleine, E., \& Bohlmeijer, E. T. (2017). Why does positive mental health buffer against psychopathology? An exploratory study on self-compassion as a resilience mechanism and adaptive emotion regulation strategy. Cognitive Therapy and Research, 41(3), 459-468. https://doi.org/10.1007/ s10608-016-9774-0

Turk, F., \& Waller, G. (2020). Is self-compassion relevant to the pathology and treatment of eating and body image concerns ? A systematic review and meta-analysis. Clinical Psychology Review, 79, 101856. https:// doi.org/10.1016/j.cpr.2020.101856

Van Orden, K. A., Cukrowicz, K. C., Witte, T. K., \& Joiner, T. E. (2011). Thwarted belongingness and perceived burdensomeness: Construct validity and psychometric properties of the Interpersonal Needs Questionnaire. Psychological Assessment, 24(1), 197e215

Vannucci, A., \& Ohannessian, C. M. (2018). Body image dissatisfaction and anxiety trajectories during adolescence. Journal of clinical child and adolescent psychology : the official journal for the Society of Clinical Child and Adolescent Psychology, American Psychological Association, Division 53, 47(5), 785-795. https://doi.org/10.1080/15374416.2017.1390755

Vargas-Medrano, J., Diaz-Pacheco, V., Castaneda, C., Miranda-Arango, M., Longhurst, M. O., Martin, S. L., Ghumman, U., Mangadu, T., Chheda, S., Thompson, P. M., \& Gadad, B. S. (2020). Psychological and neurobiological aspects of suicide in adolescents: Current outlooks. Brain, Behavior, \& Immunity - Health, 7, 100124. https://doi.org/10.1016/j.bbih.2020.100124

Voss, C., Ollmann, T. M., Miché, M., Venz, J., Hoyer, J., Pieper, L., Höfler, M., \& Beesdo-Baum, K. (2019). Prevalence, onset, and course of suicidal behavior among adolescents and young adults in Germany. JAMA Network Open, 2(10), e1914386. https://doi.org/10.1001/jamanetworkopen.2019.14386

Werner, K. H., Jazaieri, H., Goldin, P. R., Ziv, M., Heimberg, R. G., \& Gross, J. J. (2012). Self-compassion and social anxiety disorder. Anxiety, Stress and Coping, 25(5), 543-558. https://doi.org/10.1080/10615806. 2011.608842 .

Wollast, R., Riemer, A. R., Sarda, E., Wiernik, B. M., \& Klein, O. (2020). How self-compassion moderates the relation between body surveillance and body shame among men and women. Mindfulness, 11, 22982313. https://doi.org/10.1007/s12671-020-01448-w

Yang, Y., Zhang, M., \& Kou, Y. (2016). Self-compassion and life satisfaction: The mediating role of hope. Personality and Individual Differences, 98, 91-95. https://doi.org/10.1016/j.paid.2016.03.086

Zareian, B., \& Klonsky, E. D. (2020). Connectedness and suicide. In A. C. Page \& W. G. K. Stritzke, (Eds.). Alternatives to suicide: Beyond risk and toward a life worth living. Elsevier. https://doi.org/10.1016/B9780-12-814297-4.00007-8

Zeller, M., Yuval, K., Nitzan-Assayag, Y., \& Bernstein, A. (2015). Self-compassion in recovery following potentially traumatic stress: longitudinal study of at-risk youth. Journal of Abnormal Child Psychology, 43(4), 645-653. https://doi.org/10.1007/s10802-014-9937-y

Zessin, U., Dickhäuser, O., \& Garbade, S. (2015). The relationship between self-compassion and well-being: A meta-analysis. Applied Psychology. Health and Well-Being, 7(3), 340-364. https://doi.org/10.1111/aphw. 12051

Zortea, T. C., Brenna, C., Joyce, M., McClelland, H., Tippett, M., Tran, M. M., Arensman, E., Corcoran, P., Hatcher, S., Heise, M. J., Links, P., O’Connor, R. C., Edgar, N. E., Cha, Y., Guaiana, G., Williamson, E., Sinyor, M., \& Platt, S. (2021). The impact of infectious disease-related public health emergencies on suicide, suicidal behavior, and suicidal thoughts. Crisis, 42(6), 474-487. https://doi.org/10.1027/0227-5910/ $\mathrm{a} 000753$

Publisher's Note Springer Nature remains neutral with regard to jurisdictional claims in published maps and institutional affiliations. 